\title{
Identification of a novel mutation associated with familial adenomatous polyposis and colorectal cancer
}

\author{
FEI-FENG LI ${ }^{1-3 *}$, ZHENG LIU $^{4 *}$, PENG YAN $^{4 *}$, XIN SHAO $^{4}$, XIA DENG $^{1,2}$, CHRISTINE SAM $^{2}$, \\ YING-GANG CHEN ${ }^{4}$, YONG-PENG XU ${ }^{4}$, XI-SHAN WANG ${ }^{4}$, GUI-YU WANG ${ }^{4}$ and SHU-LIN LIU ${ }^{1-3,5}$ \\ ${ }^{1}$ Genomics Research Center (One of The State-Province Key Laboratory of Biopharmaceutical Engineering), \\ Harbin Medical University; ${ }^{2}$ HMU-UCFM Centre for Infection and Genomics, Harbin Medical University; \\ ${ }^{3}$ Translational Medicine Research and Cooperation Center of Northern China, Heilongjiang Academy of Medical Sciences, \\ Harbin 150081; ${ }^{4}$ Department of Colorectal Surgery of the Second Affiliated Hospital, Harbin Medical University, \\ Harbin 150086, P.R. China; ${ }^{5}$ Department of Microbiology and Infectious Diseases, \\ University of Calgary, Calgary, AB T2N4N1, Canada
}

Received March 11, 2015; Accepted July 13, 2015

DOI: $10.3892 / \mathrm{ijmm} .2015 .2303$

\begin{abstract}
Colorectal cancer (CRC) is among the most fatal forms of solid tumor in men and women. While the majority of diagnosed CRC cases are sporadic, $15-25 \%$ of patients have a family history of adenomatous polyposis and CRC; however, the associated gene mutations remain largely unidentified. The aim of the present study was to investigate the genomes of a four-generational Chinese Han family with familial adenomatous polyposis and CRC to identify the potential genetic anomalies associated with the disease. Diagnoses were made by physical and enteroscopic examinations of all the family members. Mutational analyses of the potential CRC-associated genes were carried out by direct gene sequencing, and the statistically significant differences in polymorphisms between normal and diseased populations were determined. Multiple sequence alignment and protein modeling were conducted using the Vector NTI and DNAMAN software tools. Clinical and pathological features of all the examined patients were consistent with typical familial adenomatous polyposis (FAP) syndrome. From the genomes of these family members, a $131564 \mathrm{~T}>\mathrm{C}$ (p.1125Val $>$ Ala) mutation was identified in exon 15 of the $A P C$ gene, and a $1126 \mathrm{G}>\mathrm{C}$ (p.324Gln $>$ His) mutation was identified in exon 12 of the MUTYH gene. The $131564 \mathrm{~T}>\mathrm{C}$
\end{abstract}

Correspondence to: Professor Gui-Yu Wang, Department of Colorectal Surgery, The Second Affiliated Hospital, Harbin Medical University, Harbin, Heilongjiang 150086, P.R. China

E-mail: guiywang@gmail.com

Professor Shu-Lin Liu, Harbin Medical University, Harbin, Heilongjiang 150081, P.R. China

E-mail: slliu@ucalgary.ca

${ }^{*}$ Contributed equally

Key words: colorectal cancer, familial adenomatous polyposis, $A P C, M U T Y H$, environmental risk factors mutation co-segregated with the affected individuals in the family and was specifically associated with the incidence of CRC $(\mathrm{P}=0.018<0.05)$. The $1125 \mathrm{Val}$ residue was highly conserved in the APC protein, and the p.1125Val>Ala mutation led to changes in the secondary structure and hydrophilicity of the APC protein. In conclusion, the $A P C$ gene mutation $131564 T>C$ is associated with FAP and the pathogenesis of CRC.

\section{Introduction}

Colorectal cancer (CRC) is among the most fatal forms of solid tumor in men and women worldwide (1), with over 96,000 new cases of colon cancer and 40,000 new cases of rectal cancer diagnosed annually in the US (2). While the majority of CRC cases are sporadic, $15-25 \%$ of patients have a family history $(3,4)$, and $5 \%$ are diagnosed with inherited CRC syndrome (5). A number of genes have been implicated in the pathogenesis of CRC, such as tumor-suppressor genes (APC, TP53 and CDKN2A), proto-oncogenes (KRAS and HRAS) and DNA repair genes $(M U T Y H)(6)$; however, specific mutations in these genes have not been identified in numerous CRC patients.

Hereditary colorectal polyposis includes a range of disorders passed on through autosomal dominant inheritance, and is divided into Lynch syndrome and familial adenomatous polyposis (FAP) (7). Lynch syndrome is characterized by the absence of polyposis (8), a positive family history and high risk for developing CRC, and a predisposition for extracolonic malignancies (such as endometrial, ovarian and gastric carcinomas) (9). Patients suspected of having Lynch syndrome are first tested for germline mutations in the mismatch repair gene. Patients without polyposis or polyposis family history, and not presenting Lynch syndrome should undergo genetic counseling to determine the cancer risk (1).

Polyposis syndrome is one of the most common syndromes associated with familial CRC, and is involved with a number of diseases, including FAP, mutY Homolog (E. coli) (MUTYH)-associated polyposis (MAP), Peutz-Jeghers syndrome and juvenile polyposis $(10,11)$. However, the majority 
of the familial CRC cases do not present polyposis, and potentially associated gene mutations are largely unknown (12). Adenomatous polyposis coli (APC), a key regulator of $\beta$-catenin in the Wnt/ $\beta$-catenin signaling pathway, has a critical role in several fundamental cell processes, including cell division and signal transduction, particularly in tumor suppression $(13,14)$. Several mutations and deletions, as well as promoter methylation, have been identified in the $A P C$ gene (15). Of significance, a number of those genetic or epigenetic changes have also been described in FAP syndrome, and more than two-thirds of CRC and adenomas have somatic mutations in the $A P C$ gene $(16,17)$. In addition to $\mathrm{CRC}$, mutations of $A P C$ have been reported in other tumors, including cancers in the liver (4), stomach (5-7), lung (8), breast (9) and the brain (cerebellar medulloblastoma) (10). However, the role of these types of mutations in the development of tumors has not been fully elucidated (11-13). The present study reports a novel mutation on exon 15 of the $A P C$ gene in four generations of a Chinese family with FAP and 200 sporadic cases of adenomatous polyposis, and furthermore, suggests a potential mechanism by which this mutation contributes to the pathogenesis of CRC.

\section{Materials and methods}

Study population and DNA collection. The members of a four-generational Chinese Han family with familial adenomatous polyposis (FAP) (Fig. 1), 200 sporadic adenomatous polyposis cases and 220 normal controls (Table I) were included in this study, which was conducted at the Second Affiliated Hospital of Harbin Medical University (Harbin, China). Written informed consent was obtained from each participant (or guardian for all the participants $<18$ years of age) and the study was reviewed and approved by the Ethics Committee of Harbin Medical University, consistent with the 1975 Declaration of Helsinki. The medical history was recorded in detail for all the enrolled participants. Each patient received physical and enteroscopic examinations. Genomic DNA was extracted from peripheral blood leukocytes of each participant using standard protocols.

DNA analysis. The exons and splicing sites of the $A P C$ and MUTYH genes were amplified by polymerase chain reaction (PCR) with the primers (data not shown), and the PCR products were sequenced using standard protocols (18) for mutational analysis.

Statistical analysis of disease-associated polymorphisms. Relevant polymorphisms were determined by DNA sequencing for all the family members. The prevalence of these polymorphisms among 200 sporadic adenomatous polyposis cases and 220 normal controls was subsequently analyzed. Statistical analyses were performed using $\chi^{2}$ tests to calculate the odds ratios and P-values using SPSS software (version 19.0; IBM Corp., Armonk, NY, USA).

Multiple sequence alignment and analysis of protein models. From the NCBI website (http://www.ncbi.nlm.nih.gov/), the APC and MUTYH protein sequences of various species were obtained and multiple-sequence alignments of the proteins were conducted using Vector NTI software (Life Technologies, Grand Island, NY, USA). The protein structures of the mutant
Table I. Clinical characteristics of the population used for polymorphism-association analyses.

\begin{tabular}{lcc}
\hline Parameter & $\begin{array}{c}\text { Sporadic adenomatous } \\
\text { polyposis }\end{array}$ & Control \\
\hline Sample, $\mathrm{n}$ & 200 & 220 \\
Male/female, $\mathrm{n}$ & $120 / 80$ & $105 / 115$ \\
Age, years & $58.65 \pm 12.13$ & $59.36 \pm 4.21$ \\
\hline
\end{tabular}

and wild-type proteins were predicted and analyzed by Swiss-model software (version 3.5) (19-22), and DNAMAN software (Lynnon Corp., Quebec, Canada).

\section{Results}

Clinical characteristics. The proband was a 32-year-old male (II:5; Fig. 1), admitted for diarrhea and weight reduction over the course of one year. The medical history of the patient revealed similar clinical features for $\sim 5$ years, however, the symptoms were treated without systematic examination for a diagnosis. Physical examination showed that the abdomen of the patient was slightly distended and nontender. Blood analysis showed the presence of a significant anemia; however, there was no bleeding or clots on rectal examination. Colonoscopy revealed numerous polyps ( $>100)$ measuring between $0.2-2 \mathrm{~cm}$ in diameter along the colon and rectum, confirmed as tubular adenoma with low-grade dysplasia. A mass was observed in the transverse colon measuring $3.0 \times 3.0 \mathrm{~cm}$. Biopsy of the polyp revealed typical adenomatous polyp features, and biopsy of the tumor demonstrated moderately differentiated adenocarcinoma. Endoscopic examination of the upper gastrointestinal system showed multiple gastric polyps in the fundus and upper body. Pathological examination confirmed fundic gland polyps. A computed tomographic scan also revealed tumors in the transverse colon; however, there was no evidence of liver or lymph node metastases.

In this four-generation family, there were 7 affected individuals with FAP syndrome that showed numerous polyps along the colon and rectum (Fig. 2); 1 affected member with endometrial cancer, 3 with the $A P C$ mutation but no corresponding clinical features, and 42 unaffected individuals (Table II). All the diagnoses were confirmed by three colorectal cancer specialists. There was no history of other systemic abnormalities in the family.

DNA analysis. Sanger sequencing of the amplified fragments in two affected family members identified a single base alteration, 131564T >C (Fig. 3), in exon 15 of the APC gene (GI:324) located at 5q21-q22, resulting in the substitution of Val to Ala at codon 1125 (p.1125Val>Ala), and a single base alteration, $1126 \mathrm{G}>\mathrm{C}$ (Fig. 3) in exon 12 of the MUTYH gene (GI:4595) located at $1 \mathrm{p} 34.1$, resulting in the substitution of Gln to His at codon 324 (p.324Gln>His). The remaining coding sequence of the two genes showed no other changes.

Further sequence analysis revealed that the $131564 \mathrm{~T}>\mathrm{C}$ alteration in the $A P C$ gene was co-segregated with all the affected individuals in the family (except III:4, 21 and 25; analyzed in the discussion). However, the $1126 \mathrm{G}>\mathrm{C}$ alteration 


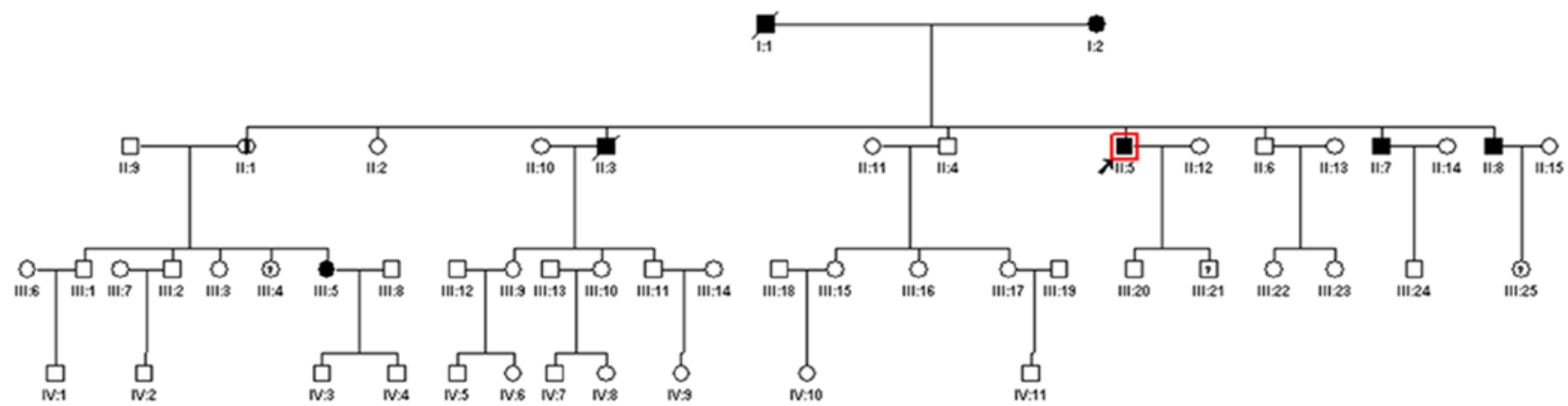

Figure 1. Pedigree of a four-generational Chinese Han family afflicted with familial adenomatous polyposis (FAP). Squares and circles indicate males and females, respectively. Filled symbols denote a diseased status. Empty symbols with a question mark inside denote mutation carriers with no clinical features. Normal individuals are shown as empty symbols.
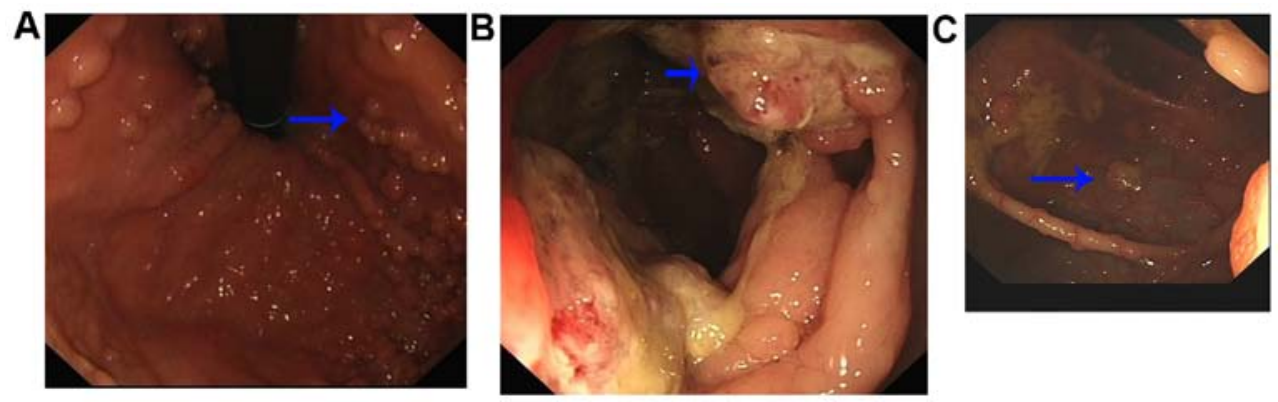

Figure 2. Enteroscopic examination of the proband individual (II:5). Images of the affected individual II:5 showed numerous polyps (arrows) measuring between $0.2-2 \mathrm{~cm}$ in diameter along the colon and rectum, confirmed as tubular adenoma with low-grade dysplasia. Endoscopic examination of the upper gastrointestinal system showed multiple gastric polyps in the fundus and upper body. (A) Numerous polyps (arrow) along the colon and rectum; (B) tubular adenoma (arrow) with low grade dysplasia; (C) Polyps (arrow) measured about $2 \mathrm{~cm}$ in diameter. There was no evidence of liver or lymph node metastases.

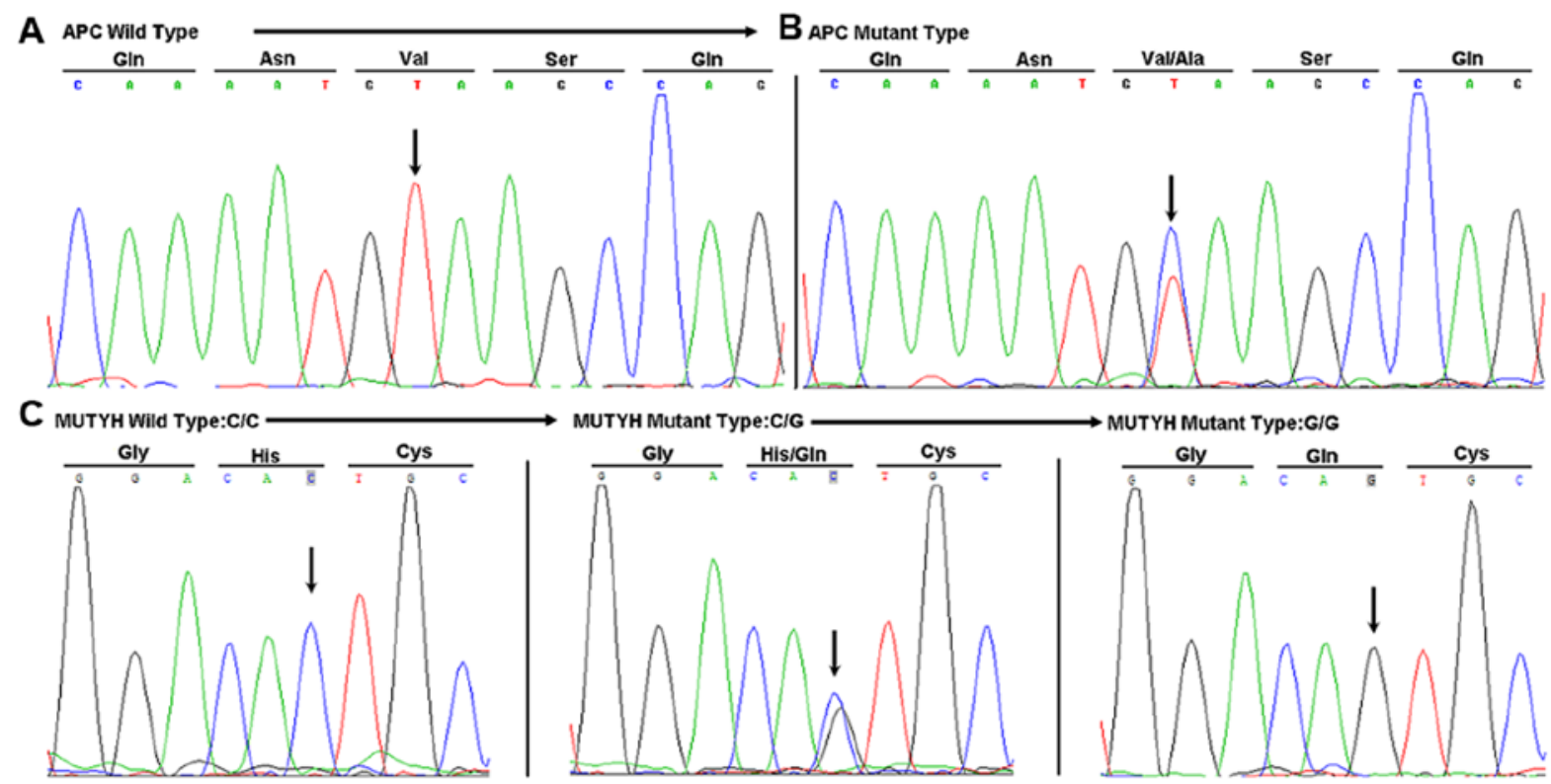

Figure 3. DNA sequence chromatogram of the $131564 \mathrm{~T}>\mathrm{C}$ mutation in $A P C$ and $1126 \mathrm{G}>\mathrm{C}$ variation in $M U T Y H$. (A) A representative DNA sequence chromatogram of the unaffected family members; 220 normal controls and 195 patients with sporadic adenomatous polyposis. (B) A representative DNA sequence chromatogram of the affected family members, III:4, III:21 and III:25, and 5 sporadic adenomatous polyposis patients. (C) DNA sequence chromatogram of the three polymorphisms, G/G, G/C and C/C, identified in the $M U T Y H$ gene in all family members, and the population used for disease-association analyses.

in the MUTYH gene was not co-segregated with any affected individuals in the family (data not shown).
Statistical analysis of the polymorphisms associated with disease. To further test any possible associations between the genetic 


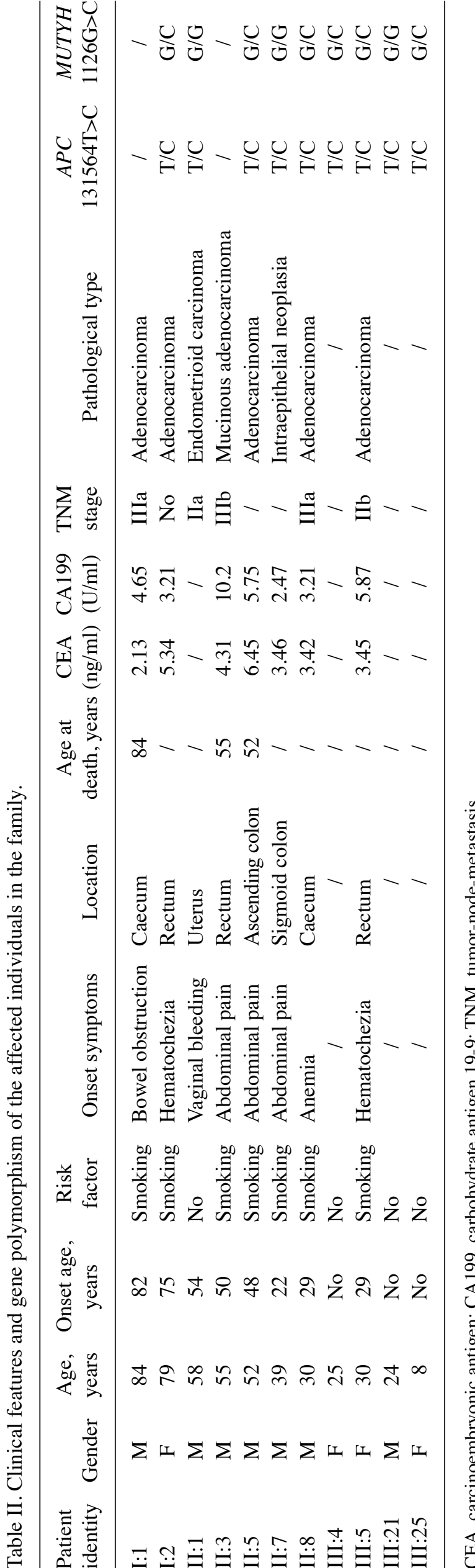

Table III. Genotype and allele frequency of the 131564T $>C$ mutation and $1126 \mathrm{G}>\mathrm{C}$ variation in 200 Chinese Han sporadic adenomatous polyposis patients and 220 non-CRC controls.

\begin{tabular}{|c|c|c|}
\hline Gene/variation & $\begin{array}{c}\text { SAP, } \\
\text { frequency }(\%)\end{array}$ & $\begin{array}{c}\text { Control, } \\
\text { frequency }(\%)\end{array}$ \\
\hline \multicolumn{3}{|c|}{ MUTYH/1126G $<\mathrm{C}$} \\
\hline \multicolumn{3}{|c|}{ Genotype } \\
\hline $\mathrm{G} / \mathrm{G}$ & 75 (37.5) & $81(36.8)$ \\
\hline $\mathrm{G} / \mathrm{C}$ & $105(52.5)$ & $104(47.3)$ \\
\hline $\mathrm{C} / \mathrm{C}$ & $20(10.0)$ & $35(15.9)$ \\
\hline \multicolumn{3}{|l|}{ Allele } \\
\hline G & $255(63.8)$ & $266(60.5)$ \\
\hline $\mathrm{C}$ & $145(36.3)$ & $174(39.5)$ \\
\hline \multicolumn{3}{|c|}{$A P C / 131564 \mathrm{~T}>\mathrm{C}$} \\
\hline \multicolumn{3}{|c|}{ Genotype } \\
\hline $\mathrm{T} / \mathrm{T}$ & $195(97.5)$ & $220(100.0)$ \\
\hline $\mathrm{T} / \mathrm{C}$ & $5(2.5)$ & $0(0.0)$ \\
\hline $\mathrm{C} / \mathrm{C}$ & $0(0.0)$ & $0(0.0)$ \\
\hline \multicolumn{3}{|l|}{ Allele } \\
\hline $\mathrm{T}$ & $395(98.8)$ & $440(100.0)$ \\
\hline $\mathrm{C}$ & $5(1.3)$ & $0(0.0)$ \\
\hline
\end{tabular}

CRC, colorectal cancer; SAP, sporadic adenomatous polyposis.

mutations and CRC, polymorphism-association analyses were conducted and the $131564 \mathrm{~T}>\mathrm{C}$ variation in the $A P C$ gene was clearly associated with the risk of $\mathrm{CRC}(\mathrm{P}=0.018<0.05)$; however, there was no statistical significance between the $1126 \mathrm{G}<\mathrm{C}$ variation in the MUTYH gene and CRC (Tables III and IV). The Hardy-Weinberg equilibrium test was also conducted for the CRC patients and the control population, and identified that they were in line with the Hardy-Weinberg equilibrium.

Evolutionary conservation of protein across the species. APC and MUTYH protein sequences were compared across multiple species including birds, fish, rodents and primates. Multiple-sequence alignment analysis showed that with the exception of Saccoglossus kowalevskii, Danio rerio and Xenopus laevis, the $1125 \mathrm{Val}$ residue in the APC protein was highly conserved, but the $324 \mathrm{Gln}$ residue in the MUTYH protein was only conserved in rodents and primates (Fig. 4).

$3 D$ modeling of protein structure. The secondary structures, hydrophobicity and hydrophilicity of the wild and mutant proteins were also compared. The online bioinformatics Swiss-model software (version 3.5) was used to predict the wild-type and mutant APC protein structure. The p.1125Val>Ala mutation made minor changes in $\sim 10$ amino acids within the secondary structure. For hydrophilicity, $\sim 700$ local amino acids were changed in the mutant APC protein; however, the hydrophobicity exhibited fewer changes (data not shown). The p.1125Val>Ala mutation also exerted a minor effect on the tertiary structure of the protein (Fig. 5). 
A

$\downarrow$ Variation Site

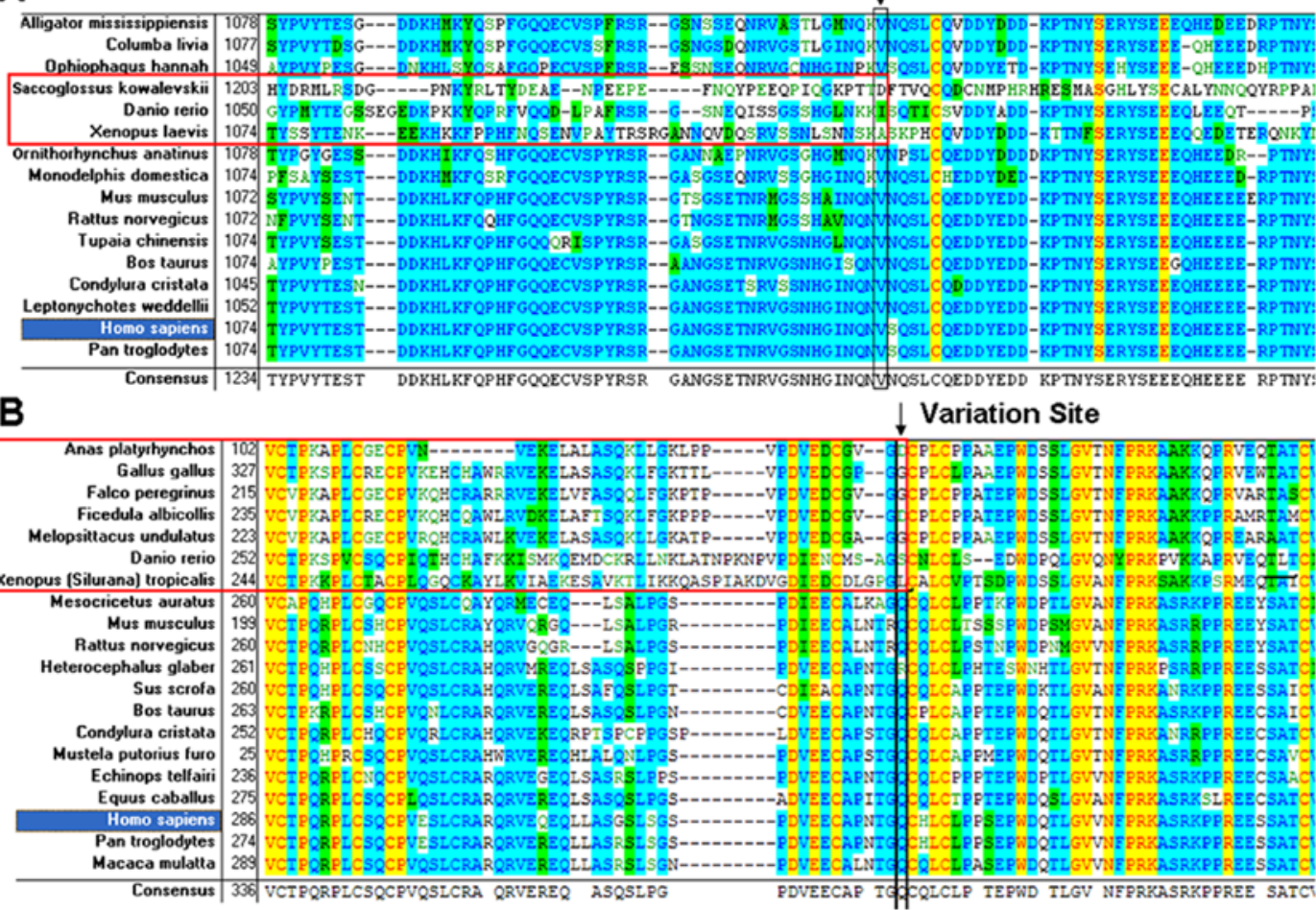

Figure 4. Analysis of protein sequences across species. (A) Multiple-sequence alignment of the adenomatous polyposis coli (APC) protein family. (B) Multiplesequence alignment of the mutY Homolog (E. coli) (MUTYH) protein family. The 1125Val residue in APC was more highly conserved compared to the 324Gln residue in the MUTYH protein.

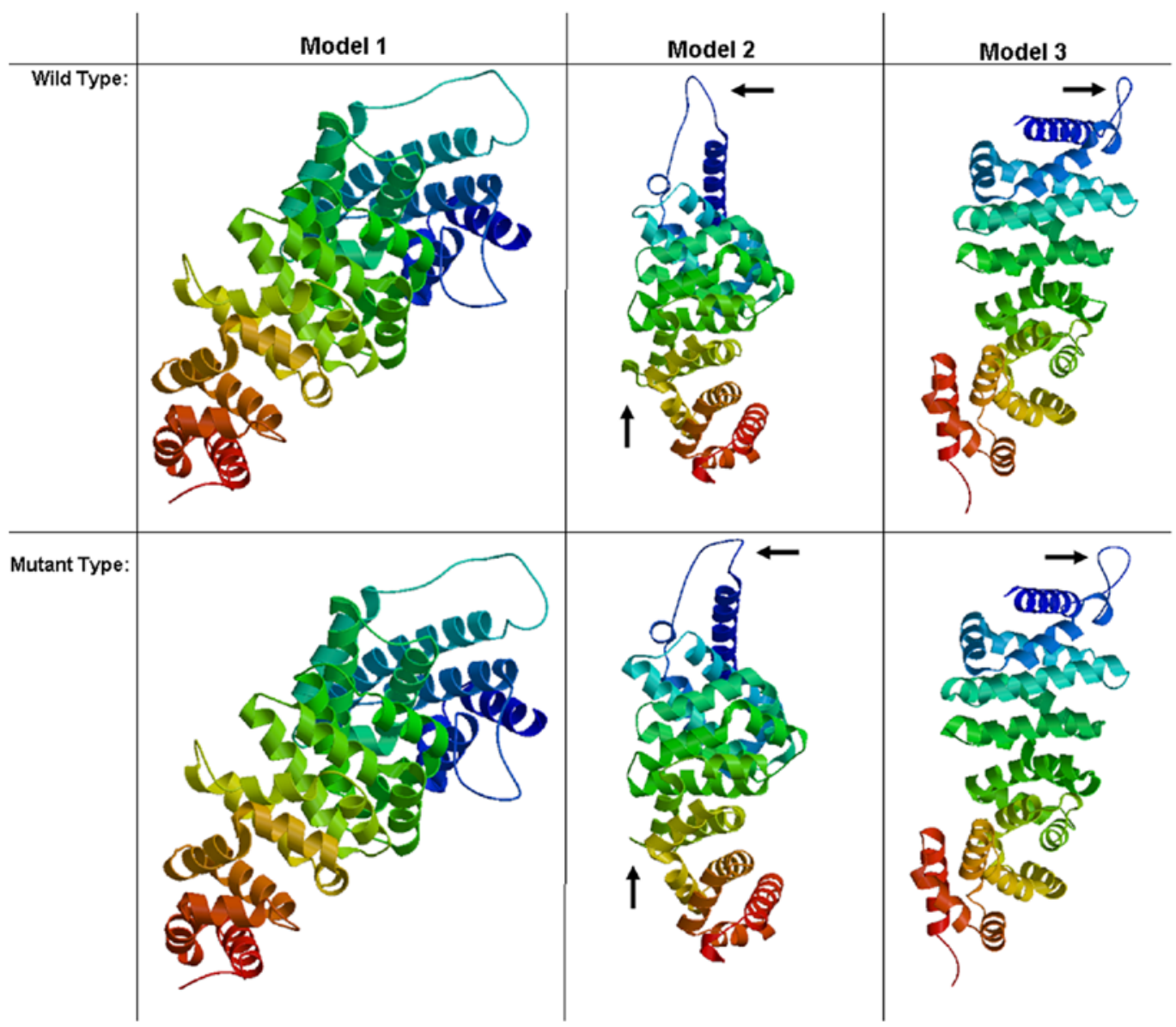

Figure 5. Comparison of wild-type and mutant adenomatous polyposis coli protein tertiary structure. The p.1125Val>Ala mutation exerted minor changes on the space of the peptide chain of the tertiary structure of the protein (arrows). 
Table IV. Associations with the risk of sporadic adenomatous polyposis in the Chinese populations with the 131564T $>\mathrm{C}$ mutation within $A P C$, but not the $1126 \mathrm{G}>\mathrm{C}$ variation in $M U T Y H$.

\begin{tabular}{|c|c|c|c|c|c|c|c|c|c|}
\hline \multirow[b]{2}{*}{ Gene/variation } & \multirow[b]{2}{*}{ Type } & \multicolumn{4}{|c|}{ Pearson $\chi^{2}$} & \multicolumn{4}{|c|}{ Pearson's R } \\
\hline & & Value & $\begin{array}{l}\text { Min. } \\
\text { count }^{\mathrm{a}}\end{array}$ & df & $\begin{array}{l}\text { Asymp. sig. } \\
\text { (2-sided) }\end{array}$ & Value & $\begin{array}{c}\text { Asymp. } \\
\text { std. error }^{\mathrm{b}}\end{array}$ & $\begin{array}{c}\text { Approx. } \\
\mathrm{T}^{\mathrm{c}}\end{array}$ & $\begin{array}{c}\text { Approx. } \\
\text { sig. }\end{array}$ \\
\hline \multirow[t]{2}{*}{ MUTYH $/ 1126 \mathrm{G}<\mathrm{C}$} & Genotype & $3.382^{\mathrm{a}}$ & 26.19 & 2 & 0.184 & 0.049 & 0.048 & 1.011 & $0.313^{\mathrm{d}}$ \\
\hline & Allele & $0.966^{\mathrm{a}}$ & 151.90 & 1 & 0.326 & 0.034 & 0.034 & 0.982 & $0.326^{\mathrm{d}}$ \\
\hline \multirow[t]{2}{*}{$A P C / 131564 \mathrm{~T}>\mathrm{C}$} & Genotype & $5.566^{\mathrm{a}}$ & 2.38 & 1 & 0.018 & -0.115 & 0.026 & -2.369 & $0.018^{\mathrm{d}}$ \\
\hline & Allele & $5.533^{\mathrm{a}}$ & 2.38 & 1 & 0.019 & -0.081 & 0.018 & -2.357 & $0.019^{\mathrm{d}}$ \\
\hline
\end{tabular}

${ }^{\mathrm{a}}$ Minimum expected count; ${ }^{\mathrm{b}}$ not assuming the null hypothesis; ${ }^{\mathrm{c}}$ using the asymptotic standard error assuming the null hypothesis; ${ }^{\mathrm{d}} \mathrm{based}$ on normal approximation.

The degree of change caused by the p.324Gln>His variation in the MUTYH protein was less than the changed caused by the p.1125Val>Ala variation to the APC protein (data not shown).

\section{Discussion}

Familial adenomatous polyposis (FAP) is a disease of autosomal dominant inheritance, with the main clinical manifestations consisting of multiple adenomatous polyps formed in the colon and rectum of affected patients (23). Approximately $80 \%$ of sporadic colorectal tumors are caused by mutations in the APC gene (24), and recently, two non-conservative mutations, Y165C and G382D, were identified in the MUTYH gene (25). The MUTYH gene encodes a DNA glycosylase that is involved in the repair of oxidative DNA damage. These MUTYH gene mutations were shown to cause an increased tendency of somatic $\mathrm{CG} \rightarrow \mathrm{AT}$ transversion in the $A P C$ gene in several colorectal adenoma or carcinoma patients (26). Further research revealed that $7-10 \%$ of FAP patients exhibit MUTYH mutations $(27,28)$, several of which can enhance the spontaneous mutator phenotype resulting in the accumulation of 8-oxoguanine (oxoG) DNA in response to oxidative stress (29). These two MUTYH mutations, Y165C and G382D, have been shown to reduce the activity of mutY in removing A from G:A mismatches in E.coli, and have also demonstrated a decrease in activity of the human MUTYH enzyme in the excision of A opposite 8-oxoG, which ultimately led to the formation of tumors $(30,31)$. This suggests that the MUTYH gene has an important role in the development of FAP, $A P C$-associated colorectal tumors and the generation of $A P C$ mutations.

In the present study, a c.131564T $>C$ (p.Val1125Ala) mutation in the $A P C$ gene was identified, which was co-segregated with disease in a multigenerational family afflicted with FAP. This mutation was not found in unaffected family members or in 220 random subjects selected from a normal population that served as a control group. Notably, 5 patients out of 200 with sporadic adenomatous polyposis also had the p.Val1125Ala mutation. Taken together, the frequency of this $A P C$ mutation was high in the sporadic adenomatous polyposis population, and the mutation was possibly the main cause of disease in the family studied.
The way in which one amino acid substitution in the APC protein can lead to the phenotypic changes observed in FAP is not fully understood. The present results demonstrate that the p.1125Val>Ala mutation results in minor changes in the secondary and tertiary structure, as well as hydrophilicity. The region of the APC protein from codon 1265 to 2035 is the binding site for $\beta$-catenin, and is essential for $\beta$-catenin degradation $(32,33)$. Mutations in this functional domain can cause changes in $\beta$-catenin binding, which is believed to have an important role in the pathogenesis of FAP (34). FAP patients with mutations in this subunit (particularly beyond codon 1309 or 1444) are more likely to develop desmoid disease, which is more severe than patients with mutations in other regions of the $A P C$ gene $(33,35)$. Around $21 \%$ of patients with desmoid tumors had $A P C$ mutations downstream of the 1444 codon, and similar mutations were identified in only $4.1 \%$ of patients with FAP (33). In the present study, the mutation identified in the Chinese Han family was in the 1125 codon (downstream of the 1444 codon), and the main clinical features of the patients were adenocarcinoma and numerous polyps along the colon and rectum. Therefore, this suggests that the 1125 codon is not as important for the function of the APC protein as codon 1265-2035, which is the binding site for $\beta$-catenin $(32,33)$.

A c. $1126 \mathrm{G}>\mathrm{C}$ (p.324Gln $>$ His) variation in the MUTYH gene was also identified. The majority of CRC patients with MUTYH mutations exhibit fewer polyps, and in certain cases have no polyps; and only extremely few cases have $>500$ polyps (23). However, certain MUTYH mutation CRC patients may develop secondary cancers in the skin, ovary, bladder and breast. In the present study, one patient in the family had endometrial cancer; however, the majority presented with adenocarcinoma and numerous polyps $(>100)$ along the colon and rectum. Furthermore, the c.1126G $>\mathrm{C}$ (p.324Gln $>$ His) variation in the MUTYH gene was not co-segregated with the studied family, and was also not associated with sporadic adenomatous polyposis disease. Taken together, the effects of the c.1126G $>\mathrm{C}$ (p.324Gln $>$ His) mutation in the MUTYH gene are negligible with regards to cancer development in this family.

The present clinical investigation showed that the affected family members with the T/C-APC mutation were either of relatively old age or were reported smokers. The 
average age of onset of the disease is 48 years, ranging from 21 to 70 years (36). Notably, certain younger $A P C$-mutation carriers have no clinical features of the disease, suggesting that age may be a potential risk factor for FAP. While certain risk factors can increase the chance of developing colorectal polyps or colorectal cancer, such as increased age (37) and smoking (38), the development of CRC from adenomatous polyps can be prevented through intensive colorectal screening (39).

In conclusion, a Chinese FAP family with adenocarcinoma and numerous polyps along the colon and rectum, in which several gene variants that may have a role in the pathogenesis of this disease were identified, was reported. The c.131564T $>C$ (p.Val1125Ala) mutation in the APC gene was co-segregated with the patients with the disease in this family, and was also directly associated with sporadic adenomatous polyposis disease.

\section{Acknowledgements}

The authors would like to thank the patients and the family members for their cooperation and participation in the present study. The study was supported by a grant from the Heilongjiang Innovation Research Foundation for Graduate Studies (no. YJSCX2014-10HYD); grants of the National Natural Science Foundation of China (nos. NSFC81271786, 81110378, 30970119, 81030029 and 81272706); a grant from the Natural Science Foundation of Heilongjiang Province (no. QC2013C086); and a grant from the Science Foundation of Health Department of Heilongjiang Province (no. 2012-452).

\section{References}

1. Knopperts AP, Nielsen M, Niessen RC, Tops CM, Jorritsma B, Varkevisser J, Wijnen J, Siezen CL, Heine-Bröring RC, van Kranen HJ, et al: Contribution of bi-allelic germline MUTYH mutations to early-onset and familial colorectal cancer and to low number of adenomatous polyps: Case-series and literature review. Fam Cancer 12: 43-50, 2013.

2. Siegel R, Ma J, Zou Z and Jemal A: Cancer statistics, 2014. CA Cancer J Clin 64: 9-29, 2014.

3. Lovett E: Family studies in cancer of the colon and rectum. Br J Surg 63: 13-18, 1976.

4. Stephenson BM, Finan PJ, Gascoyne J, Garbett F, Murday VA and Bishop DT: Frequency of familial colorectal cancer. Br J Surg 78: 1162-1166, 1991.

5. Tops CM, Wijnen JT and Hes FJ: Introduction to molecular and clinical genetics of colorectal cancer syndromes. Best Pract Res Clin Gastroenterol 23: 127-146, 2009.

6. Järvinen HJ: Hereditary cancer: Guidelines in clinical practice. Colorectal cancer genetics. Ann Oncol 15 (Suppl 4): iv127-iv131, 2004.

7. Hampel H, Frankel WL, Martin E, Arnold M, Khanduja K, Kuebler P, Clendenning M, Sotamaa K, Prior T, Westman JA, et al: Feasibility of screening for Lynch syndrome among patients with colorectal cancer. J Clin Oncol 26: 5783-5788, 2008.

8. Umar A, Boland CR, Terdiman JP, Syngal S, de la Chapelle A, Rüschoff J, Fishel R, Lindor NM, Burgart LJ, Hamelin R, et al: Revised Bethesda Guidelines for hereditary nonpolyposis colorectal cancer (Lynch syndrome) and microsatellite instability. J Natl Cancer Inst 96: 261-268, 2004.

9. Lynch HT and Lynch JF: What the physician needs to know about Lynch syndrome: an update. Oncology (Williston Park) 19: 455-464, 466, 469, 2005.

10. Farrington SM, Tenesa A, Barnetson R, Wiltshire A, Prendergast J, Porteous M, Campbell $\mathrm{H}$ and Dunlop MG: Germline susceptibility to colorectal cancer due to base-excision repair gene defects. Am J Hum Genet 77: 112-119, 2005.
11. Cleary SP, Cotterchio M, Jenkins MA, Kim H, Bristow R, Green R, Haile R, Hopper JL, LeMarchand L, Lindor N, et al: Germline MutY human homologue mutations and colorectal cancer: A multisite case-control study. Gastroenterology 136: 1251-1260, 2009.

12. Aaltonen LA, Salovaara R, Kristo P, Canzian F, Hemminki A, Peltomäki P, Chadwick RB, Kääriäinen $H$, Eskelinen $M$, Järvinen $\mathrm{H}$, et al: Incidence of hereditary nonpolyposis colorectal cancer and the feasibility of molecular screening for the disease. N Engl J Med 338: 1481-1487, 1998.

13. Bodmer WF, Bailey CJ, Bodmer J, Bussey HJ, Ellis A, Gorman P, Lucibello FC, Murday VA, Rider SH, Scambler P, et al: Localization of the gene for familial adenomatous polyposis on chromosome 5. Nature 328: 614-616, 1987.

14. Schneikert J and Behrens J: The canonical Wnt signalling pathway and its APC partner in colon cancer development. Gut 56: 417-425, 2007.

15. Hanson CA and Miller JR: Non-traditional roles for the Adenomatous Polyposis Coli (APC) tumor suppressor protein. Gene 361: 1-12, 2005.

16. Nagase H and Nakamura Y: Mutations of the APC (adenomatous polyposis coli) gene. Hum Mutat 2: 425-434, 1993.

17. Miyoshi Y, Nagase H, Ando H, Horii A, Ichii S, Nakatsuru S, Aoki T, Miki Y, Mori T and Nakamura Y: Somatic mutations of the APC gene in colorectal tumors: Mutation cluster region in the APC gene. Hum Mol Genet 1: 229-233, 1992.

18. Tan ZX, Li FF, Qu YY, Liu J, Liu GR, Zhou J, Zhu YL and Liu SL: Identification of a known mutation in Notch 3 in familiar CADASIL in China. PLoS One 7: e36590, 2012.

19. Biasini M, Bienert S, Waterhouse A, Arnold K, Studer G, Schmidt T, Kiefer F, Cassarino TG, Bertoni M, Bordoli L, et al: SWISS-MODEL: Modelling protein tertiary and quaternary structure using evolutionary information. Nucleic Acids Res 42: W252-8, 2014

20. Arnold K, Bordoli L, Kopp J and Schwede T: The SWISS-MODEL workspace: A web-based environment for protein structure homology modelling. Bioinformatics 22: 195-201, 2006.

21. Kiefer F, Arnold K, Künzli M, Bordoli L and Schwede T: The SWISS-MODEL Repository and associated resources. Nucleic Acids Res 37: D387-D392, 2009.

22. Guex N, Peitsch MC and Schwede T: Automated comparative protein structure modeling with SWISS-MODEL and Swiss-PdbViewer: A historical perspective. Electrophoresis 30 (Suppl 1): S162-S173, 2009.

23. Barrow P, Khan M, Lalloo F, Evans DG and Hill J: Systematic review of the impact of registration and screening on colorectal cancer incidence and mortality in familial adenomatous polyposis and Lynch syndrome. Br J Surg 100: 1719-1731, 2013.

24. Markkanen E, Dorn J and Hübscher U: MUTYH DNA glycosylase: The rationale for removing undamaged bases from the DNA. Front Genet 4: 18, 2013.

25. Al-Tassan N, Chmiel NH, Maynard J, Fleming N, Livingston AL, Williams GT, Hodges AK, Davies DR, David SS, Sampson JR, et al: Inherited variants of MYH associated with somatic G:C-->T:A mutations in colorectal tumors. Nat Genet 30: 227-232, 2002.

26. Jones S, Emmerson P, Maynard J, Best JM, Jordan S, Williams GT, Sampson JR and Cheadle JP: Biallelic germline mutations in MYH predispose to multiple colorectal adenoma and somatic G:C-->T:A mutations. Hum Mol Genet 11: 2961-2967, 2002.

27. Filipe B, Baltazar C, Albuquerque C, Fragoso S, Lage P, Vitoriano I, Mão de Ferro S, Claro I, Rodrigues P, Fidalgo P, et al: APC or MUTYH mutations account for the majority of clinically well-characterized families with FAP and AFAP phenotype and patients with more than 30 adenomas. Clin Genet 76: 242-255, 2009.

28. Pezzi A, Roncucci L, Benatti P, Sassatelli R, Varesco L, Di Gregorio C, Venesio T, Pedroni M, Maffei S, Reggiani Bonetti L, et al: Relative role of APC and MUTYH mutations in the pathogenesis of familial adenomatous polyposis. Scand J Gastroenterol 44: 1092-1100, 2009.

29. Ruggieri V, Pin E, Russo MT, Barone F, Degan P, Sanchez M, Quaia M, Minoprio A, Turco E, Mazzei F, et al: Loss of MUTYH function in human cells leads to accumulation of oxidative damage and genetic instability. Oncogene 32: 4500-4508, 2013.

30. Chmiel NH, Golinelli MP, Francis AW and David SS: Efficient recognition of substrates and substrate analogs by the adenine glycosylase MutY requires the C-terminal domain. Nucleic Acids Res 29: 553-564, 2001.

31. Pope MA and David SS: DNA damage recognition and repair by the murine MutY homologue. DNA Repair (Amst) 4: 91-102, 2005. 
32. Sturt NJ, Gallagher MC, Bassett P, Philp CR, Neale KF, Tomlinson IP, Silver AR and Phillips RK: Evidence for genetic predisposition to desmoid tumours in familial adenomatous polyposis independent of the germline APC mutation. Gut 53: 1832-1836, 2004.

33. Schiessling S, Kihm M, Ganschow P, Kadmon G, Büchler MW and Kadmon M: Desmoid tumour biology in patients with familial adenomatous polyposis coli. Br J Surg 100: 694-703, 2013.

34. Polakis P: The adenomatous polyposis coli (APC) tumor suppressor. Biochim Biophys Acta 1332: F127-F147, 1997.

35. Bertario L, Russo A, Sala P, Eboli M, Giarola M, D'amico F, Gismondi V, Varesco L, Pierotti MA and Radice P; Hereditary Colorectal Tumours Registry: Genotype and phenotype factors as determinants of desmoid tumors in patients with familial adenomatous polyposis. Int J Cancer 95: 102-107, 2001.

36. Ali M, Kim H, Cleary S, Cupples C, Gallinger S and Bristow R: Characterization of mutant MUTYH proteins associated with familial colorectal cancer. Gastroenterology 135: 499-507, 2008.
37. U.S. Preventive Services Task Force: Screening for colorectal cancer: U.S. Preventive Services Task Force recommendation statement. Ann Intern Med 149: 627-637, 2008.

38. Morrison DS, Batty GD, Kivimaki M, Davey Smith G, Marmot M and Shipley M: Risk factors for colonic and rectal cancer mortality: Evidence from 40 years' follow-up in the Whitehall I study. J Epidemiol Community Health 65: 1053-1058, 2011.

39. Levin B, Smith RA, Feldman GE, Colditz GA, Fletcher RH Nadel M, Rothenberger DA, Schroy PS III, Vernon SW and Wender R; National Colorectal Cancer Roundtable: Promoting early detection tests for colorectal carcinoma and adenomatous polyps: a framework for action: the strategic plan of the National Colorectal Cancer Roundtable. Cancer 95: 1618-1628, 2002. 